\title{
ENTRE LA PANTALLA CHICA Y LA PANTALLA GRANDE: LOS DOCUMENTALES REALIZADOS EN VIDEO PARA LA TELEVISIÓN ARGENTINA HACIA LA DÉCADA DEL OCHENTA
}

\author{
BETWEEN THE SMALL SCREEN AND THE BIG SCREEN: \\ THE DOCUMENTARY SERIES RECORDED ON VIDEO FOR THE ARGENTINE \\ TELEVISION TOWARDS THE EIGHTIES
}

ENTRE LA TELA PENQUENA E A TELA GRANDE: OS DOCUMENTAÁRIOS REALIZADOS EM VIDEO PARA A TELEVISAO ARGENTINA EM TORNO DA DÉCADA DE OITENTA

Paola Judith Margulis Bolsista de Pós-doutorado do Conicet-Argentina e-mail:paomargulis@yahoo.com

\begin{abstract}
Resumo
Apesar de sua importância para a geração de identidades coletivas e individuais, mediando e permeando a construção da realidade, o documentário televisual argentino pós-ditadura forma uma lacuna que, até o momento, tem sido escassamente explorada pelos estudos sobre cinema e televisão. O presente artigo propõe acrescentar algo ao campo dos estudos sobre Comunicação e Cultura a partir da reconstrução histórica das condições de produção e características principais do ciclo de documentários Misiones, su tierra y su gente (1985), realizado pelo reconhecido diretor Eduardo Mignogna. Na medida em que sua lógica de produção tem prevista a formação e movimento de saberes específicos entre pares, este caso é sumamente relevante para reconstruir e analisar parte do processo de especialização e institucionalização do documentário argentino.
\end{abstract}

Palavras chave: Televisão; documentário; transição democrática

\section{Abstract}

Despite its relevance in the creation of collective and individual identities, mediating and permeating in the construction of reality, the post-dictatorship Argentine documentary television series are still a pending area which, thus far, has been scarcely explored by studies on cinema and television. This article aims at contributing to the field of studies on Communication and 
Culture departing from the historical reconstruction of the production conditions and main features of the documentary television program Misiones, su tierra y su gente (1985), made by the renowned director Eduardo Mignogna. Insofar as its production logic plans the formation and transfer of specific knowledge among pairs, this case is of utmost importance for analyzing part of the specialization and institutionalization of Argentine documentary films.

Key words: Television; documentary; transition to democracy

\section{Resumen}

A pesar de su importancia en la generación de identidades colectivas e individuales, mediando y permeando en la construcción de la realidad; el documental televisivo argentino postdictadura constituye aún un área pendiente, que hasta el momento no ha sido explorado por los estudios sobre cine y televisión. El presente artículo se propone realizar un aporte al campo de los estudios sobre Comunicación y Cultura a partir de la reconstrucción histórica de las condiciones de producción y características principales del ciclo documental Misiones, su tierra y su gente (1985) del reconocido realizador Eduardo Mignogna. En la medida que su lógica de producción tiene prevista la formación y traspaso de saberes específicos entre pares, este caso resulta sumamente relevante para reconstruir y analizar el proceso de especialización $e$ institucionalización del documental argentino.

Palabras clave: Televisión; documental; transición democrática

\section{Introducción}

Hacia la transición democrática argentina, la televisión -aún cuando había sido percibida como uno de los medios oficiales de la dictadura, ${ }^{1}$ y a pesar de seguir intervenida- empezó a evidenciar ciertos cambios que indican una renovación. Ésta se expresó en la incorporación de nuevos temas y aproximaciones de corte cultural que hicieron foco en el redescubrimiento de la cultura popular, los sectores marginados, la cultura urbana, etc. Parte de dicha renovación se expresó a su vez en la incorporación paulatina del documental a través de distintos formatos. Además de la producción de programas de orientación periodístico-documental de periodicidad semanal, la pequeña pantalla también incluyó en su programación ciclos especiales de corte no ficcional. Constituidos, mayormente, sobre la base de 4 a 6 capítulos, los especiales tuvieron cierta recurrencia, principalmente, desde mediados de la década del ochenta. Se trató de iniciativas generadas a partir del apoyo de determinados organismos estatales no necesariamente

\footnotetext{
${ }^{1}$ La última dictadura militar argentina tuvo lugar entre los años 1976 y 1983.
} 
vinculados al medio televisivo, como la Secretaría de Ciencia y Técnica de la Nación, el Ministerio de Salud y Acción Social, el Gobierno de la Provincia de Misiones, etc. Su realización respondió, en muchos casos, a la finalidad de divulgar y valorizar ante la mirada del público la función de determinados entes y organismos, frente a la renovación que presuponía el retorno democrático. Si bien escasas, estas convocatorias circunscriptas a temas precisos, dieron la oportunidad a documentalistas independientes de ingresar a la televisión a través de un sistema de coproducciones con el Estado (HERMIDA, 1990). Tal como notan Graciela Taquini y Rodrigo Alonso, algunas de estas innovadoras producciones independientes, sirvieron también como un laboratorio experimental en torno del video:

Esto introduce un aire diferente en una televisión basada en programas "en vivo" o en productos enlatados altamente estandarizados -como los unitarios o las telenovelas- aportando su espíritu renovador al fermento del que surgirían las primeras realizaciones experimentales de nuestro país. (ALONSO Y TAQUINI, 1999, p. 13-14).

El presente artículo se propone aportar a la reconstrucción del proceso de especialización e institucionalización del documental argentino, a partir del abordaje de las condiciones de producción del especial Misiones, su tierra y su gente (1985) dirigido por Eduardo Mignogna. Se trata, posiblemente, de la producción menos conocida de un realizador que ha logrado un gran renombre en el campo cinematográfico a lo largo de su carrera. Haciendo uso de recursos innovadores, este especial dirigido por Mignogna sienta ciertas características técnicas y estilísticas que serían luego recuperadas por otras producciones de corte periodístico-documental realizadas para televisión. A su vez, se trata de un caso que logra articular la producción documental cinematográfica y televisiva, en un momento en el que ambos medios solían regirse por lógicas de funcionamiento sumamente diferenciadas.

A partir de la reconstrucción histórica de las condiciones de producción de Misiones, su tierra y su gente, el presente trabajo propone un primer acercamiento a un tipo de realización que a pesar de su trascendencia, no ha sido aún relevado ni analizado por los estudios sobre cine y televisión. En términos específicos, el artículo intentará estudiar qué tipo de articulaciones y negociaciones se dan entre los condicionantes de producción y la dimensión estilística del especial, en un momento en el que el documental televisivo argentino conservaba aún ciertos rasgos de pionerismo. En particular, interesará observar el grado de especialización de las 
prácticas documentales, en base a la constitución de grupos de trabajo y la separación y distinción de funciones (WILLIAMS, 1982, p. 34-35). En lo que respecta más específicamente al proceso de especialización, el aprendizaje y traspaso de saberes entre pares constituyen aspectos por completo relevantes, en la medida en que funcionan como indicadores del grado de profesionalización e institucionalización del documental (DEBRET, 2007). Dicho enfoque presupone entender al documental como una "disciplina de principios y códigos de prácticas" (CORNER, 1996, p. 4); o en términos de Trish FitzSimons, Pat Laughren y Dugald Williamson, como un campo de prácticas históricamente situado (FITZSIMONS, LAUGHREN Y DUGALD, 2011, p. 10); dado que la definición misma del documental implica una negociación entre discurso y práctica (PLANTINGA, 2010, p. 9).

Con ese objetivo en miras, una parte importante del estudio estará abocado a la reconstrucción de los principales rasgos del ciclo, desde la perspectiva ofrecida por los agentes realizadores y técnicos-, apoyándonos en entrevistas en profundidad como herramienta principal. Dado que el realizador Eduardo Mignogna ha fallecido, su trayectoria será abordada en forma oblicua, a través de las experiencias de sus compañeros y colaboradores. Dicha labor de entrevistas será complementada con el análisis del programa televisivo y de otros documentos como artículos de prensa, grillas de programación, guiones, fotografías, publicaciones, convenios sindicales, etc.-; y el análisis de la secuencia de créditos del ciclo.

En función de lo recién expuesto, el programa Misiones, su tierra y su gente será cotejado en base a ciertos aspectos que resultan sensibles a la especialización de la práctica documental: a) los procedimientos de producción, b) los tiempos y recursos disponibles, c) la especialización del grupo de colaboradores, y d) la posibilidad de traspaso de saberes entre pares. El estudio de estos elementos, nos permitirá analizar el grado de especialización del documental; brindándonos indicios para analizar las potencialidades y los límites que ofreció el medio televisivo para la producción documental durante el período abordado.

\section{EI Sistema Provincial de Teleducación y Desarrollo (SIPTED)}

Misiones, su tierra y su gente (1985) constituye uno de los varios especiales que Eduardo Mignogna dirigió para la televisión argentina. Con anterioridad el director había realizado Desafío a la vida (1984) sobre discapacidad; y posteriormente realizaría el capítulo "Mocosos y chiflados" correspondiente al ciclo Apuntes sobre cultura popular (1986); además de los 
especiales La vivienda de los ángeles I y II (1988); y La salud de los ángeles I y II (MIGNOGNA, 1988) sobre bienestar social. Misiones, su tierra y su gente comparte características fundamentales con éstos y otros ciclos de especiales documentales anteriormente mencionados - los cuales se caracterizaban por convocar a realizadores de cine, en un marco de producción generado y financiado por distintas áreas de gobierno-; por fuera de las estructuras institucionales de los canales televisivos. Pero más allá este factor, la experiencia y condiciones de producción de Misiones, su tierra y su gente remiten a un caso excepcional, el cual pone en juego una instancia formativa de cuadros profesionales. En la medida en que dicho factor resulta sensible al proceso de especialización e institucionalización del documental, hemos optado por concentraros en las características de este caso. Por otra parte, el carácter excepcional de este ciclo también radica en su perspectiva localista. En un país tan centralizado como la Argentina, en el que aproximadamente un tercio de la población y el grueso de la producción mediática se concentra en la ciudad Buenos Aires; apuestas como las de Misiones, su tierra y su gente constituyen toda una novedad, en la medida en que han sido concebidas para dar respuesta a las necesidades educativas y comunicacionales de una región específica del país.

Compuesto por 4 capítulos -"Los Colonos", "Aborígenes", "Misiones Jesuíticas" y "Educación rural"-, Misiones, su tierra y su gente constituye uno de los ciclos -junto con el docudrama Horacio Quiroga, entre personas y personajes- que la dupla Eduardo Mignogna Graciela Maglie (el primero como director y la segunda como investigadora y en algunos casos como co-guionista) realizaría en el marco del Sistema Provincial de Teleducación y Desarrollo (SIPTED). El SIPTED fue creado a fines de 1984 dentro de la órbita del Ministerio de Bienestar Social y Educación de la Provincia de Misiones -a cargo del Ministro Sábato Esteban Romano-, para ejecutar sistemas alternativos de educación (Ley $\mathrm{N}^{\circ} 2161$ ). Dicho organismo tomó como modelo inicial, un exitoso sistema implantado en Canadá; país que padecía el aislamiento de parte de su población debido a las condiciones geográficas y factores climáticos, lo cual obstaculizaba la asistencia escolar. La provincia de Misiones sufría problemas de incomunicación, debido a diversos accidentes geográficos y a la falta de una adecuada construcción vial. Se trata de una región con más del noventa por ciento de fronteras internacionales, y casi la mitad de su población viviendo en zonas rurales. En dichas condiciones, los chicos misioneros debían caminar un promedio de tres kilómetros para llegar a la escuela (LA RAZON, 29/11/85). 
El eje central del proyecto del SIPTED era subordinar recursos tecnológicos al servicio de la educación. Mientras que el sistema canadiense se organizó en función de la tecnología del satélite; en Argentina, con distintos condicionantes económicos y culturales, el SIPTED trabajó sobre otra base tecnológica, sirviéndose de los medios locales junto con una vía no mediatizada de comunicación, basada en encuentros de intercambio cara a cara (ZANOTTI, 2003, p. 6). A grandes rasgos, el SIPTED nucleaba tres grandes áreas: 1) la instrumentación del Programa de Educación Secundaria Abierta (ESA); 2) la organización de un programa a partir del trabajo en Clubes Teleducativos $(\mathrm{CT}) ;^{2} 3$ ) y por último, la producción teleducativa audiovisual (ZANOTTI, 1995). Esta última función - en la que nos concentraremos- se propuso captar la diversidad social y cultural de la provincia de Misiones mediante una sostenida producción documental. Tal como detalla un trabajo teórico elaborado por la antropóloga y documentalista Ana Zanotti -quien participó de la experiencia formativa del SIPTED y continuó como realizadora de dicho programa por varias décadas-, el SIPTED

[...] desde el principio orientó también sus intenciones hacia el trabajo profesionalmente encarado, desde lo creativo y desde lo tecnológico. Esto se expresó en la contratación ya desde su momento fundacional, de un equipo productor de reconocimiento nacional encabezado por Eduardo Mignogna, con Graciela Maglie, como su co-guionista. El ciclo Misiones, su tierra y su gente sirvió de laboratorio inicial en el terreno a quienes desde entonces formamos parte del equipo de realización local (ZANOTTI, 1995, p. 78).

Tal como puede apreciarse, la formación de cuadros especializados en documental y el traspaso de saberes en términos generacionales constituían objetivos estratégicos del área de producción audiovisual del SIPTED. La idea era generar documentales de alta calidad sobre temáticas de interés para la provincia, formando, en paralelo un cuadro de realizadores locales, encargados de darle continuidad a la producción audiovisual de dicho organismo, luego de concluido el especial Misiones, su tierra y su gente. Para la realización de dicho ciclo, Mignogna convocó a un equipo de reconocida trayectoria que tenía a su cargo -además de su rol técnico específico- la formación de colaboradores locales del SIPTED. Según explica Graciela Maglie (coordinadora de la investigación y guionista):

\footnotetext{
${ }^{2}$ Se trataba de centros de comunicación -escolares, comunitarios, parroquiales- donde se organizaban programas acordes a los intereses de los grupos, mediante el ejercicio de su participación creadora y con el acompañamiento de un promotor teleducativo y el recurso teleducativo del video (Zanotti, 1995).
} 
[...] el módulo de trabajo que planteaba el SIPTED era contratar, armar un equipo con gente que ya tuviera antecedentes profesionales y cada uno de nosotros teníamos una suerte de meritorio, de doble, que nos acompañaba, al que nosotros formábamos, para que una vez que nos retiráramos de la provincia ellos siguieran haciendo; y es lo que ocurrió (MAGLI, 2010).

La experiencia funcionó con éxito. Como resultado de dicha práctica formativa -que incluyó también estadías de capacitación en la Tele Université de Quebec- se constituyó un equipo de producción audiovisual dentro del SIPTED integrado por jóvenes comunicadores sociales, antropólogos, sociólogos, etc. (ZANOTTI, 2011); herederos de la tradición implantada por el grupo dirigido por Mignogna. La formación de cuadros, trascendió incluso la experiencia fundante del SIPTED, como evidencia el hecho de que algunos de sus integrantes continuaran su carrera como documentalistas luego de abandonar dicha institución años más tarde.

Con el tiempo, el SIPTED produciría numerosísimos materiales de tratamiento documental (los ciclos Misiones y sus pueblos, Encuentros Populares, Voces de vida, Nuestras escuelas, En aquel entonces..., entre muchos otros (ZANOTTI, 1995)); contando ya en 1985 con más de 70 horas de programas educativos (LA RAZON, 29/11/85). Estas producciones se difundieron siempre a nivel masivo por canales de aire y de cable de la Provincia de Misiones, y se utilizaron como soporte didáctico en experiencias como los Tele-clubes. En el caso de los ciclos dirigidos por Mignogna, fueron también transmitidos por las emisoras de Capital Federal. Pero por fuera de estos canales de distribución masiva, los materiales audiovisuales se difundían en las comunidades que habían sido objeto de esos documentales. Tal como describe Maglie:

El modo en que se difundía, y nosotros queríamos que se difundiera así, era ir a las comunidades y mostrarles la película. Este era el sentido, para que recuperaran su propia historia, su propia dignidad como sujetos. Este era el plan (MAGLIE, 2010).

De esa forma, la experiencia del SIPTED funcionó como un espacio de experimentación tanto en lo que respecta a las modalidades de producción y formación, como en lo que respecta a la creación documental. 


\section{Eduardo Mignogna: entre la literatura, el cine y la televisión}

Habiéndose formado como periodista, y con una fuerte vocación de escritor que le valió importantes premios; ${ }^{3}$ Eduardo Mignogna comenzó a vincularse con el oficio del cine a través de la publicidad. A partir del proceso abierto por la transición democrática, Mignogna retornó de Italia -lugar donde se había exiliado durante los años de dictadura-, y dirigió su primer largo documental, Evita, quien quiera oír que oiga ${ }^{4}$ (1984) en el contexto de la transición democrática. Con posterioridad, sería convocado para dirigir el especial Desafio a la vida-sobre discapacidad, el primero de varios ciclos documentales que realizaría para la televisión. Si bien sus antecedentes hasta ese momento se subordinaban al documental, lo hacían desde un lugar que tenía prevista la hibridación y la mezcla de géneros; apoyado en un férreo trabajo de guión. En lo que respecta a la dimensión institucional, más allá de las variantes y características de cada uno de estos especiales, las producciones de Mignogna tendieron a realizarse en forma independiente, por fuera de la estructura de los canales de televisión.

Cineasta de oficio - profesión que tendría una continuidad en paralelo a sus trabajos para televisión-, la modalidad característica de sus producciones y la lógica que empleaba para la conformación de grupos de trabajo, conservan rasgos característicos del campo cinematográfico. De esta forma -salvo contadas excepciones en las que los canales aportaron técnicos o equiposla realización y postproducción se hacía en forma independiente y se negociaba luego con el canal, una vez el producto terminado. De ese modo, las emisoras no imponían procedimientos, ni intervenía en decisiones estéticas o concernientes a la conformación de los grupos de trabajo.

Para estos especiales documentales, Eduardo Mignogna trabajaba con colaboradores provenientes del campo cinematográfico. Tal como explica Rodolfo Hermida -realizador que habría de desarrollar con posterioridad programas televisivos de orientación documental que mantendrían una modalidad de producción independiente, similar a la de Mignogna-:

\footnotetext{
${ }^{3}$ Eduardo Mignogna recibió el premio de la Revista Marcha (Montevideo, Uruguay) por la novela En la cola del cocodrilo (1971); su libro de cuentos Cuatrocasas (1976) ganó el premio de Casa de las Américas (La Habana, Cuba); fue galardonado con el Primer Premio en el Concurso Latinoamericano del cuento policial por su obra Lastenia (1975); y Tigres y Alondras (1983) le valió la Mención espacial en el concurso de la Revista Plural (México). Mignonga también publicó en 1984 un libro con el guión de su film Evita, quien quiera oír que oiga.

${ }^{4}$ Evita, quien quiera oír que oiga retrata distintos pasajes de la vida de la mítica figura de María Eva Duarte de Perón. Articulado a partir de entrevistas, materiales de archivo y reconstrucción ficcional, el film narra el viaje que realiza en ferrocarril la joven Eva desde Junín hasta Buenos Aires, transcurso en el cual vislumbra el rol histórico que le tocaría encarar a lo largo de su vida adulta.
} 
En la [televisión] argentina el que manda es el productor ejecutivo o el productor general, el director es el switcher; salvo cuando los directores vienen de afuera con el producto enlatado, son directores y ponen el sello total de directores, y claramente son gente de cine. [...] O sea que en todos esos ciclos hay atrás gente de cine, y se nota en la realización. (HERMIDA, 2012).

Si bien a la hora de aceptar estos trabajos para la televisión Mignogna no era aún el realizador consagrado que llegaría a ser, su función se apoyaba sobre la alta jerarquía que caracteriza a un realizador en el campo cinematográfico. Su figura era vislumbrada -no simplemente a partir de una función técnica-, sino a partir de su potencial artístico. Mignogna mismo no se consideraba a sí mismo "un hombre de televisión", pero despreciaba la enemistad que muchas veces podía verificarse entre los trabajadores de dicho medio y el cine (CLARIN, 05/01/86). Al respecto, el realizador sostiene:

Como el material de TV es de utilización diaria, casi obliga a que en términos de producción se trabaje con mayor rapidez y menor cuidado de las formas que en el cine. Muchas veces un largometraje no es más que un teleteatro; sólo que con mucho más tiempo de realización, presupuesto y cuidado que el producto televisivo. De cualquier modo es cierto que cada vez que aparece un director de cine en la televisión es mirado como invasor, alguien del que, antes que nada, se supone que desprecia al medio. Por su lado, el director piensa que se notará el desconocimiento de un lenguaje apenas no acierte a nombrar un VTR, un VCN, jerga en la que la gente de la televisión está astutamente entrenada (CLARIN, 05/01/86).

Los documentalistas televisivos se muestran conscientes de que tanto la dinámica del medio, como los acelerados tiempos de pre y post-producción vuelven a estos programas objeto de prejuicio por parte de aquellos que provienen del cine. La gente de cine no tiene en cuenta reflexiona la consagrada documentalista televisiva Clara Zappettini- el ejercicio y el "esfuerzo que constituye hacer un mediometraje por semana" (ZAPPETTINI, 02/12/10). Otra de las desestimaciones del documental televisivo se relaciona con las supuestas limitaciones expresivas de la televisión, frente a un potencial y a una plasticidad mayores, atribuidas a las tecnologías de captación y exhibición cinematográficas. Zappettini coincide con Mignogna al no ver en el soporte tecnológico - la utilización de fílmico en el caso del cine, o de video en el caso de la televisión-, un factor decisivo, ni un determinante en lo que respecta a la dimensión estética. Por el contrario, la realizadora ubica la clave en los tiempos de narración y fundamentalmente, en las pausas y aceleraciones, en las transiciones, en la relación entre sonido e imagen. Serían estos 
aspectos -sostiene Zappettini-, los que diferenciarían al documental cinematográfico respecto del televisivo, y no el soporte o su forma de circulación (entrevista concedida por Clara Zappettini, 02/12/10). El trabajo de Mignogna para la televisión pareciera intentar conciliar ambos mundos; presentando documentales que capitalizan las modalidades y tiempos de trabajo propios del cine, a disposición del potencial de alcance de la televisión.

\section{Composición de los equipos de trabajo}

En líneas generales, la estructura de le televisión argentina no responde a una lógica de departamentalización por áreas (Deportes, Documental, Infantiles, Espectáculos, etc.), razón por la cual, programas orientados hacia temáticas diversas comparten, en los hechos, productores, camarógrafos, editores y procedimientos comunes. Contenido dentro de la estructura de un canal, ciertos aspectos sensibles a la realización documental -como la composición de un equipo de trabajo especializado y el manejo de los tiempos de producción- se vieron claramente determinados por las exigencias propias de la lógica televisiva y su ajustado manejo del tiempo. Si bien la realización de documentales no requiere en sí misma del apoyo de grupos estables de trabajo (integrados por los mismos colaboradores); en el marco de la estructura de la televisión, el trabajo con equipos compuestos por personal estable, funcionó como una forma de palear una falencia institucional; operando como una herramienta para contrarrestar la falta de especialización. En dicho contexto, el trabajo con grupos estables habilitaba un grado de capacitación del personal técnico -asistentes, camarógrafos, editores, sonidistas, etc.- en torno de aspectos, temáticas y cuidados inherentes a las prácticas documentales; generando un compromiso y una mirada compartida. ${ }^{5}$

En contraposición a la lógica que caracterizaba hacia la década del ochenta a los programas documentales realizados dentro de las estructuras de los canales de televisión, las producciones independientes de Mignogna tendían a asemejarse más a las dinámicas particulares de la industria cinematográfica. Pero a diferencia de ciertas características propias del trabajo en cine -donde luego de la finalización de un contrato, los trabajadores no siempre vuelven a

\footnotetext{
${ }^{5}$ Estas afirmaciones se desprenden de las entrevistas realizadas a distintos realizadores y colaboradores que hicieron toda una carrera en el marco de la estructura institucional de los canales de televisión, como Roberto Vacca, Clara Zappettini, Marta Prada, Carlos Laino, entre otros.
} 
coincidir en un próximo film-, Mignogna tenía la costumbre convocar a la misma gente y armar equipos estables, los cuales resultaban recurrentes entre un proyecto y otro (sean para cine o televisión). Posiblemente, habría que ver también allí, un compromiso compartido y una afinidad que excede la simple elección en base a la formación de oficio. El posicionamiento político de Mignogna, tendió a evidenciarse a través de algunas de sus obras, como Evita, quien quiera oír que oiga (1984) -film que fue percibido por la prensa del período como una mirada desde el peronismo sobre un tramo de la historia argentina-; pero también, a través de proyectos que tendrían mucho menor difusión, como El beso del olvido (1991). ${ }^{6}$ Este último film habría estado motivado por los indultos concedidos-hacia el comienzo del primer gobierno menemista- a distintos autores de crímenes de lesa humanidad perpetrados durante la última dictadura.

En líneas generales, el grupo recurrente convocado por Mignogna estaba conformado por Graciela Maglie como guionista, César D’Angelillo o Pablo Mari en la compaginación y José Luis Díaz en la dirección de sonido. Un rasgo distintivo que diferenciaba el trabajo de Mignogna respecto de las producciones realizadas dentro de las estructuras de los canales de televisión, es la valorización e incorporación de una función central en el cine, y prácticamente inexistente en la televisión de la época: la Dirección de fotografía. En los trabajos de Mignogna, este rol era habitualmente cubierto por Ricardo de Deangelis o Marcelo Camorino. De un modo que resultaba escasamente habitual en el contexto mediático argentino de la época, Mignogna se servía de la tecnología del video teniendo un especial cuidado por la dimensión estética. En el caso particular que nos convoca, resulta importante destacar que Mignogna, le daba al soporte magnético un tratamiento cinematográfico, utilizando una sola cámara -a diferencia de la televisión que normalmente articulaba varias-; y sin el rigor que exige el set de televisión en términos de iluminación (CLARIN, 05/01/86). La iniciativa era experimentar con las potencialidades estéticas que por aquel entonces ya ofrecía el video. ${ }^{7}$

Este trabajo de experimentación en torno del video realizado por Mignogna y su equipo, marcaría un precedente, y tendría una continuidad en la producción de otros realizadores como Roberto Cenderelli, Rodolfo Hermida o Carlos Sorín, entre otros (ALONSO Y TAQUINI, 1999,

\footnotetext{
${ }^{6}$ El beso del olvido es un film ensayístico-documental, que incluye como parte de su argumentación, entrevistas realizadas a Eva Giberti, Horacio Verbitsky, Graciela Maglie, Luis Moreno Ocampo, León Rozitchner, José M. Pasquini Duran, Graciela Fernández Meijide, Julio César Strassera, Jacobo Timmerman, entre otros.

${ }^{7}$ El video analógico había sido incorporado a la televisión argentina en el año 1977 (Ulanovsky, Itkin y Sirvén, 2006: 384-385).
} 
p. 13). Tal como explica Rodolfo Hermida -quien considera a Mignogna como un pionero en la realización de video para televisión-:

Nosotros usamos el video con un criterio de cine. [...] Bajo el punto de vista del ritmo del montaje, de los encuadres. Más que como se usaba en televisión, que se usaba como una estética de news, de noticieros, descuidada, porque importaba más la instantaneidad de la nota (...). En realidad hacíamos cine electrónicamente, ésa era la diferencia (HERMIDA, 2012).

Por otra parte, el hecho de trabajar con un equipo estable influía en que todos conocieran el estilo del director y trabajaran en forma orgánica. Según recuerdan varios de sus colaboradores, sus opiniones eran pedidas continuamente, e incluso se sentían motivados a participar en rubros que estaban fuera de su incumbencia técnica. ${ }^{8}$ Esta modalidad participativa se apoyaba en el compromiso de cada uno de los rubros en lo que concierne a la técnica, pero también a las inquietudes sociales que involucraban muchos de estos proyectos documentales. De esa forma, la estabilidad de los equipos de trabajo, no remitía tanto en este caso a la especialización técnica en el documental -dado que los proyectos dirigidos por Mignogna eran más bien heterogéneos, articulando diversos géneros, soportes y dispositivos-; como sí a un compromiso y criterio compartidos.

\section{Tiempos y formas de trabajo}

Esta forma de trabajo, tensionada entre el cine y la televisión, adoptaría características propias, también desde el punto de vista formal. El manejo de tiempos más holgados que los habituales en televisión, y la articulación de estrategias discursivas que buscan despegarse de los recursos pedagógicos más frecuentes en el documental tradicional, contribuyeron a generar, en su conjunto, una propuesta novedosa. Para empezar, Misiones, su tierra y su gente se distancia de otros documentales televisivos del período fuertemente identificados con la imagen de un presentador (como Historias de la Argentina secreta, La aventura del hombre, etc.). En términos generales, la existencia de un conductor suele estar justificada por la empatía que logra con la

\footnotetext{
${ }^{8}$ En ocasiones, César D'Angiolillo asistía a los rodajes, cuando su rol como compaginador no lo requería (Entrevista concedida por César D'Angiolillo, 24/08/11); el director de fotografía Ricardo Deangelis ha participado de discusiones de armado de guión con Graciela Maglie y Eduardo Mignogna (Entrevista concedida por Ricardo Deangelis, 27/01/12); y Graciela Maglie ha presenciado e intervenido en la edición de algunos programas, algo que tampoco le estaba asignado a su rol de guionista e investigadora (Entrevista concedida por Graciela Maglie, $12 / 06 / 10)$.
} 
audiencia, y su presencia, en muchos cosas, ayuda a contextualizar y explicar los distintos momentos que componen la presentación documental. En Misiones, su tierra y su gente el trabajo de investigación y de guión organiza un entramado que lejos de reponer un simple panorama informativo; intenta interpelar al espectador, a partir del trabajo en torno de problemáticas complejas que no se clausuran con la conclusión de cada capítulo. Los distintos episodios que conforman este especial, asumen la estructura de un mediometraje sin presentador, prescindiendo tanto de la guía narrativa de una voz over, como de cualquier otro recurso didáctico frecuente en el documental expositivo (NICHOLS, 1991)-como láminas, mapas, infografías, etc.-. A partir de esta propuesta, la función de aportar datos e interpretar las prácticas culturales que vemos en pantalla, es suplida por entrevistas a expertos (quizá la parte más convencional de esta propuesta, las "cabezas parlantes"), testimonios de los propios protagonistas, y en los casos en que se vuelve necesario aportar información histórica o cifras estadísticas, se recurre a intertítulos. Refiriéndose a la mirada y forma de rodaje de los documentales de Eduardo Mignogna, Ana Zanotti describe:

Si era posible decir algo desde una voz en off, pero a la vez lo podías expresar desde una situación cotidiana, bueno, ahí vos veías que Eduardo priorizaba lo cotidiano, y a lo mejor una pequeña secuencia de algo que sucedía te contaba muchísimo más, o más claramente, digamos, algo que vos podías decir [a través de locución]" (ZANOTTI, 2011).

Como rasgo distintito, el especial recurre a la voz explicativa de los mismos protagonistas, antes que a la objetividad de un narrador omnisciente. Esto se vuelve particularmente significativo en el capítulo "Los aborígenes", en el que son presentados algunos rituales y prácticas cotidianas de una comunidad de Guaraníes. Resulta ejemplificador un fragmento en el que se puede ver a un grupo de hombres jóvenes, descalzos, practicando una danza ritual hacia el amanecer. La voz que acompaña y explica estas imágenes corresponde a uno de los miembros de dicha comunidad, siendo su explicación modulada por los tonos, inflexiones y pausas que les resultan característicos. La no utilización de un comentario over implica no solamente una decisión ética y estética -cederle la voz a los miembros de una comunidad marginada-; sino que también nos habla de la economía de recursos que maneja la producción, fundamentalmente de tiempo, al contar con la posibilidad de quedarse, interaccionar y ganar la confianza de los protagonistas. 
Los tiempos de investigación, rodaje y post-producción con los que trabajaba el equipo de Eduardo Mignogna excedían por mucho a los característicos de los documentales realizados dentro de la estructura de un canal de televisión. Según observa Clara Zappettini,

Mignogna tuvo una producción que nosotros nunca tuvimos. [...] Cuando yo digo producción es que tenía más tiempo de realización. Nosotros, no. Nosotros éramos una máquina de producir [...] (ZAPPETTINI, 02/12/10).

La dificultad para lograr manejarse con amplios tiempos de producción y realización -inherente a la mecánica propia de la estructura de los canales de televisión-, constituye una de las razones por las cuales Mignogna prefería desarrollar sus obras en forma independiente. En palabras del director:

[Eduardo Mignonga] Dice que le cuesta trabajar dentro de un canal de televisión. "Las restricciones del medio chocan contra mi propia producción. No soporto esa locura del rating y encima vendo un producto caro. Pero lo mío no se encarece porque haya tal o cual figura que cobre mucho sino por el tiempo que tardo en hacer un trabajo. Una buena obra no se hace de un día para otro y, en televisión, el tiempo es plata. Lamentablemente -agrega- no le veo una salida." (LA RAZON, 12/85).

Si bien resulta habitual que los especiales cuenten con más tiempo de realización que los programas de periodicidad semanal; también es cierto que los ciclos de Mignogna, seguían lógicas y mecanismos que no eran los más corrientes para el documental televisivo argentino de la década del ochenta. Esto implica un amplio tiempo de pre-producción y de rodaje, y luego, una instancia de edición en Metrovisión, casa editora que contaba con tecnología de punta, capaz de maximizar las posibilidades que por aquel momento ofrecía el video. El resultado es un producto caro. En referencia a los capítulos de Desafio a la vida-ciclo emitido por canal 13, realizado por el equipo estable de Mignogna, utilizando recursos y procedimientos similares a los que caracterizarían más tarde a Misiones, su tierra y su gente-, el realizador sostiene:

es difícil seguir, porque estos ciclos son muy caros y aunque la televisión argentina intenta modificar su calidad, no puede pagarla. Y la producción independiente, en general, es saboteada por los medios de comunicación. Cuando una producción está bien hecha, al exhibirla por un canal pone de manifiesto las carencias de ese canal, no en cuanto a los profesionales, que son muy buenos, sino a lo limitado del presupuesto. Si tuviéramos que grabar y editar en dos días, los resultados no serían los mismos", compara. Eduardo 
Mignogna y su equipo "de gente de cine", invierte en la realización de cada programa un promedio de once jornadas de ocho horas de trabajo (LA RAZON, 28/01/85).

En otra entrevista correspondiente al mismo año, Mignogna especifica: "yo me estoy tomando seis o siete días de filmación y otros tantos de montaje para algo que habitualmente a lo que (sic) se dedica uno o dos" (TIEMPO ARGENTINO, 05/09/84).

En lo que respecta a la organización de la producción de estos especiales, estaban previstas varias etapas en las que la investigación y el trabajo de campo -que llevaron al menos tres meses (LA RAZON, 29/11/85)-, constituían el paso previo al armado del guión de cada capítulo. Esta primera base permitía comenzar con las entrevistas y otras actividades propias del rodaje. El trabajo sobre el guión resultaba exhaustivo; revirtiendo esa concepción que tiende a atribuirle a los discursos sobre lo real una cuota más alta de azar que en la ficción (debido a la relación con la realidad (COMOLLI, 2002)). La estructura del ciclo de Mignogna propone recursos narrativos específicos para cada capítulo, sin excluir la reconstrucción ficcional. Más allá de que al apelar a la ficcionalización los documentales arriesguen en cierta medida su credibilidad -dado que "[...] se produce una ruptura en el nexo indicativo entre imagen y referente histórico" (NICHOLS, 1991, p. 52)-; dicho recurso también ayuda a ganar y sostener la relación con la audiencia popular (CORNER, 1996, p. 31). Según argumenta Corner, la "proxemia de la dramatización", su capacidad de "acercarnos" ciertas problemáticas más generales; contrasta con la enfática distancia que busca un documental convencional a partir de su mezcla de observación y comentario (CORNER, 1996, p. 35). ${ }^{9}$ Dicho recurso, además de darle una gran fluidez al texto documental, ayuda a diversificar estrategias de acercamiento a un público diverso (recordemos que estaba prevista la emisión de este especial en los canales de Buenos Aires, pero también en los medios locales de la provincia de Misiones y en instancias de discusión impulsadas por los Tele-clubes).

Si bien los distintos capítulos que componen Misiones, su tierra y su gente se organizan alrededor del hilo común que constituyen las entrevistas y los testimonios de especialistas y protagonistas; existe en cada uno de ellos la explotación de recursos exclusivos. En el episodio

\footnotetext{
${ }^{9}$ John Corner utiliza esta descripción para dirigirse a un tipo particular de representación ficcional-documental, aquella correspondiente a las historias bélicas, producidas en estudios en Inglaterra hacia 1950. Pero más allá de lo puntual de esta referencia, consideramos que algunos aspectos generales de esta descripción, resultan útiles para pensar en forma más general la representación ficcional en un marco documental.
} 
dedicado a maestros rurales, el articulador común es la idea de viaje, presentando a un personaje que encarna el rol del maestro rural y se traslada, a lo largo del capítulo, a través de una geografía que se comporta necesariamente como motivación y desafío. Este elemento distintivo funciona como articulador de transiciones y separador de los distintos momentos de la narración. Algo similar ocurre en el capítulo dedicado a los colonos, donde la reconstrucción ficcional sirve para materializar prácticas habituales y rituales, correspondientes a las distintas comunidades a las que se hace alusión. Esta recreación está organizada de manera tal de ir construyendo una narración visual, ejemplificando dificultades y vivencias comunes que se desprenden de los testimonios de los colonos que se fueron asentando en Misiones. En el caso del capítulo dedicado a Misiones jesuíticas, el hilo principal es llevado adelante por uno de los agentes especializados, quien recorre varios de los espacios aludidos por los mismos núcleos informativos que el documental va desplegando -dando paso a distintas reconstrucciones ficcionales que toman lugar en ellos-. En dicho capítulo, la puesta en escena de los tramos ficcionalizados es acompañada por una evidenciación del dispositivo documental; vehiculizada a través de la puesta en cuadro de la figura del director, la exhibición de la cámara y del staff de grabación, los diálogos e indicaciones entre ellos, etc. Por su parte, el episodio sobre Aborígenes, toma la estructura cíclica de un día en la vida de los aborígenes Guaraníes, recuperando la ritualidad de sus prácticas características, y abriendo a partir de ellas un grupo de problemáticas y conflictos subyacentes a la subordinación a la "cultura de los blancos". Tanto el minucioso trabajo sobre el guión, como los tiempos holgados manejados por la producción, hacen posible en este caso, asignarle a cada capítulo una propuesta y una estética capaces de funcionar en forma autónoma. De modo que si el ciclo logra componer una serie, lo hace no a fuerza de repetición de ideas o recursos, sino a partir de la articulación de un concepto común.

\section{A modo de conclusión}

Hasta hace no mucho tiempo, el documental televisivo argentino fue objeto de variadas dificultades y prejuicios. A diferencia de lo sucedido en otros lugares del mundo fundamentalmente en Europa-, donde la televisión constituyó el principal cauce de exhibición del documental, determinando tanto los contenidos como los formatos que éste debía adoptar 
(WEINRICHTER, 2004, p. 33-34); en Argentina a este tipo de productos audiovisuales le fue muy difícil insertarse en la pequeña pantalla. Tensionado entre el prejuicio de los realizadores cinematográficos -que veían en la televisión a un medio superficial y mal pago-, la dificultad de acceso al medio televisivo, y la precariedad de recursos; el documental de televisión tendió a ser considerado "el pariente pobre del cine".

El recorrido realizado nos presenta algunas de las características fundamentales que el documental independiente tendió a asumir en el marco de la televisión argentina hacia la década del ochenta. La experiencia de los especiales, resulta ligada, de alguna manera, a la coyuntura histórica en la medida en que su producción resultó incentivada por una determinada política cultural que no tendría una continuidad en el tiempo. El motor de estos proyectos acotados no proviene de la televisión ni de la industria, sino de áreas de gobierno y de instituciones a ellas vinculadas. Así, no se observa en la televisión postdictadura un genuino interés por incorporar al documental en tanto tal; sino más bien, podría pensarse que el documental sirvió como vehículo para incorporar a dicho medio cierta perspectiva federal y el abordaje de determinadas temáticas que la política cultural del gobierno de la Unión Cívica Radical estaba interesado en difundir.

El recorrido realizado nos expone un caso en el que se articulan la técnica del cine -con saberes específicos y determinados manejos del tiempo-, y la utilización de la tecnología del video. El soporte electromagnético inicialmente había sido rechazado por el sector cinematográfico por presentar una calidad inferior al fílmico y por la dificultad para insertarlo en el circuitos de salas de exhibición; siendo en cambio rápidamente incorporado por la televisión. ${ }^{10}$ En dicho contexto de cambios, proyectos como los de Eduardo Mignogna, tienden a modular dichos supuestos, al conjugar una cultura del trabajo propia del campo cinematográfico -con el cuidado estético de una dirección de fotografía-, sobre el soporte electromagnético, asociado a la pantalla chica. Dicha propuesta, no proviene de la estructura institucional de los canales de televisión, sino que se identifica con un tipo de producción independiente de fuerte vocación cinematográfica, notablemente influenciada por el estilo personal de un realizador.

En términos generales, las experiencias de prácticas documentales en el marco de la televisión argentina en el período estudiado tienden a ser más bien escasas. Se trata de un momento en el cual el documental televisivo de realización local guardaba aún características de

\footnotetext{
${ }^{10}$ Las características y plasticidad del soporte electromagnético serían inicialmente exploradas, también, por distintos circuitos de video-arte. 
excepcionalidad. En dicho contexto, el trabajo en forma independiente (por fuera de la estructura de los canales), tendió a ofrecer algunas ventajas, como la selección de los miembros del staff de producción, y mayor flexibilidad en la utilización de recursos. En este artículo hemos estudiado el caso de Misiones, su tierra y su gente, correspondiente a uno de los realizadores que más especiales documentales ha dirigido para la televisión argentina durante la década del ochenta. En la medida en que estos proyectos fueron realizados siguiendo modalidades similares, y con equipos de trabajo estables; sus características principales se vuelven generalizables. Pero más allá de estos rasgos, la modalidad de producción independiente, por sí sola, no resulta necesariamente deudora de los procedimientos cinematográficos ni de sus procedimientos técnicos.

En lo que respecta al traspaso de conocimiento profesional, son pocas las posibilidades de intercambio de saberes entre pares que hayan podido efectuarse con éxito dentro de la institución televisiva argentina, generando un verdadero vínculo y espíritu de pertenencia. El caso del SIPTED ofrece una experiencia de carácter excepcional, donde la formación documental pudo transmitirse siguiendo objetivos precisos. Pero más allá del éxito efectivo que consiguió, dicha iniciativa permaneció circunscripta a un marco acotado, logrando un escaso impacto en las modalidades institucionales de producción de los sistemas televisivos por fuera de la provincia de Misiones. De ese modo - a diferencia de otros países donde el documental constituye una práctica profesionalizada-, la formación de cuadros se vio ligada a proyectos acotados, sin lograr filtrarse hacia la industria. Por su parte, la lógica institucional de los canales de televisión no pareciera tener previsto una especialización por áreas. Más por el contrario, las meritorias realizaciones de los pioneros del documental televisivo, tuvieron que avanzar a contrapelo del funcionamiento del medio; imponiendo un estilo allí donde la lógica institucional tendió siempre a imponer una práctica.

\section{BIBLIOGRAFÍA}

ALONSO, Rodrigo y TAQUINI, Graciela. Buenos Aires Video X. s.1.: Agencia Española de Cooperación Internacional, 1999, p. 11-60.

COMOLLI, Jean-Louis. Filmar para ver. Escritos de teoría y crítica de cine. Buenos Aires: Sumurg / FADU, 2002. 
CORNER, John. The Art of Record: A critical introduction to documentary, Manchester: Manchester University Press, 1996.

DEBRETT, Mary. Professionalizing Documentary Production, International Journal of the Arts in Society, Melbourne, Australia. v. 1, n. 3, 2007.

FITZSIMONS, Trish, LAUGHREN, Pat y WILLIAMSON, Dugald. Australian documentary: History, practices and genres. Melbourne: Cambridge University Press, 2011.

HERMIDA, Rodolfo. La TV en la Argentina, discurso presentado en Medios del Norte, Imágenes del Sur. Primer encuentro argentino-alemán sobre producción, distribución, coproducción y fomento del cine documental. Buenos Aires: Goethe-Institut Buenos Aires, 1990.

LA FERLA, Jorge (Comp.) Historia crítica del video argentino. Buenos Aires: Fund. Eduardo F. Constantini - Fundación Telefónica, 2008.

NICHOLS, Bill. La representación de la realidad. Cuestiones y conceptos sobre el documental. Barcelona: Paidós, 1991.

PLANTINGA, Carl. Rhetoric and Representation in Nonfiction Film. Cambridge: Cambridge University Press, 2010.

ULANOVSKY, Carlos, ITKIN, Silvia y SIRVÉN, Pablo. Estamos en el aire. Historia de los medios de comunicación en la Argentina. Buenos Aires: Emecé, 2006.

WEINRICHTER, Antonio. Desvíos de lo real: El cine de no ficción, Madrid: T\&B, 2004.

WILLIAMS, Raymond. Cultura: sociología de la comunicación y del arte. Barcelona: Paidós, 1982.

WINSTON, Brian . Technologies of seeing: Photography, Cinematography and Television. Londres: British Film Institute, 1996.

ZANOTTI, Ana María. Veintitantas miradas y un relato. Una aproximación audiovisual a la realidad. Tesina de Licenciatura correspondiente a la Carrera de Antropología Social, Facultad de Humanidades y Ciencias Sociales, Universidad Nacional de Misiones, Posadas - Misiones, 2005.

ZANOTTI, Ana María. A regional Educational Experience: Between Communication and Development in Misiones - Argentina: SIPTED. s/d/, 2003.

\section{FUENTES CITADAS}

LA RAZON. Los programas deben hacerse con autenticidad y veracidad, 29/11/85. 
CLARIN. Conversación con Eduardo Mignogna. Crecer es saber que hay cosas que no debo hacer, 05/01/86.

LA RAZON. Eduardo Mignogna. El francotirador de la TV argentina,12/85.

LA RAZON. Propuesta televisiva con drama y humor, 28/01/85.

TIEMPO ARGENTINO. Los trabajos y los días del múltiple Eduardo Mignogna, 05/09/84.

\section{ENTREVISTAS}

Entrevista concedida por Ana Zanotti 15/12/11.

Entrevista concedida por Clara Zappettini, 02/12/10.

Entrevista concedida por Graciela Maglie, 12/06/10.

Entrevista concedida por Rodolfo Hermida, 17/01/12.

Original recebido em: 30/02/2013

Aceito para publicação em: 20/11/2013

Resumo sobre o autor

Paola Judith Margulis

Doctora en Ciencias Sociales por la

Universidad de Buenos Aires. Coordinadora del Área de Estudios sobre Comunicación y Documental Audiovisual correspondiente a la Carrera de Ciencias de la Comunicación, Facultad de Ciencias Sociales, Universidad de Buenos Aires. Becaria postdoctoral del

Conicet 
